\title{
Prototype Pintu Air Berbasis Android dan Mikrokontroller Menggunakan Bluetooth
}

\author{
M.Irmansyah ${ }^{1}$, Junaldi $^{2}$, Arya Bima Surya ${ }^{3}$ \\ ${ }^{123}$ Jurusan Teknik Elektro Politeknik Negeri Padang \\ mirmansyah38@gmail.com \\ Kampus Politeknik Negeri Padang, Limau Manis Padang
}

\begin{abstract}
Generally, in existing dams facilitated by sluice are used to control the amount of water on that dam. This sluice is controlled by a human that has a duty to maintain the stability of the water on that dams or not to be more than existing limitation. Therefore the doorman clerk must be ready at all times and it is impossible for him to do it over time. The water gate drain human energy when open and then close it again. This tool is using as a replacement for human power. By the statement improved advanced technology development taht combines Android with Bluetooth-based Atmega 328 microcontroller instruments. This remote sluice control works automatically. The Ping sensor measures the level of the water and sluice, after that the recorded data will be processed by microcontroller and send it into the Android through Bluetooth. Besides that, the Android data that consist of water level and sluice will be captured on the LCD screen. On the other hand, the Beeb voice that getting from a buzzer will active when the level of the water sign exceeds $3 \mathrm{~cm}$. In this research, Android is used as a monitoring tool and control system remotely. Furthermore, this tool also uses a DC motor in order to open and close sluice, so it makes the water gate capable to be closed and opened based on expected distance. This system hopefully can automatically open the water gate if the water level higher than a limit position by using an android control system based on operator expectation. That way there is no human power needed to open the water gate. In other words, effectiveness and efficiency will occur.
\end{abstract}

Keywords: SRF04 PING Sensor, Arduino Uno Atmega328, L298 Motor Driver, DC Motor, Bluetooth, Android.

Abstrak - Pada bendungan-bendungan yang sudah ada, digunakan pintu air untuk mengatur banyaknya air dalam bendugan itu. Pintu air dikendalikan oleh manusia yang bertugas menjaga supaya air dalam bendungan tetap stabil. Dalam hal ini tidak melebihi batas yang sudah ada. Oleh karena itu, petugas penjaga pintu air harus siap siaga setiap saat. Tapi sangat tidak mungkin petugas itu setiap saat ada untuk menjaga pintu air. Pintu air suatu bendungan yang menguras tenaga manusia untukmembukanya lalu menutupnya kembali. Alat ini berguna sebagai pengganti tenaga manusia. Dengan pernyataan semakin berkembangnya teknologi yang canggih, dengan mengkombinasikan antara android dengan instrumen mikrokontroller Atmega 328 berbasis bluetooth. Alat pengendali pintu air jarak jauh ini bekerja secara otomatis. Sensor ping mengukur ketinggian air dan pintu air dan diolah oleh microcontroller lalu data dikirim ke android melalui bluetooth. Data pada android berupa data ketinggian air dan pintu air yang dideteksi dan akan ditampilkan pada layar LCD. Sedangkan buzzer sebagai tanda apabila air melebihi ketinggian $3 \mathrm{~cm}$ dan buzzer akan berbunyi. Pada alat ini android berfungsi sebagai alat monitoring dan control jarak jauh. Untuk dapat membuka dan menutup pintu air digunakan motor DC. Sehingga pintu air dapat dikontrol sesuai jarak perintah yang diberikan. Alat ini untuk meringankan pekerjaan serta memudahkan dalam pengendalian pintu air bendungan dengan menggunakan android berbasis bluetooth. Yang nantinya akan secara otomatis membuka pintu air jika ketinggian air telah melewati batas dengan mengontrol menggunakan android yang sesuai dengan keinginan operator. Dengan begitu tidak dibutuhkan lagi tenaga manusia untuk membuka pintu air. Dengan kata lain akan terjadi efektifitas dan efisiensi

Kata kunci: Sensor PING SRF04, Arduino Uno Atmega328, Driver Motor L298, Motor DC, Bluetooth, Android.

(C) 2018 Elektron Jurnal Ilmiah

\section{PENDAHULUAN}

Ilmu pengetahuan dan teknologi yang semakin berkembang pada saat ini yang menciptakan teknologi canggih khususnya teknologi komunikasi yaitu ponsel pintar atau smartphone yang berbasis dengan android. Ponsel pintar atau smartphone merupakan pengembangan dari ponsel-ponsel lama yang didalamnya ditambahkan sebuah OS atau operational system. Sistem pengendalian dan sistem pemantuan merupakan sistem yang mampu mengendalikan dan mengawasi sebuah kejadian atau suatu kegiatan yang dapat terjadi pada suatu tempat atau sebuah lokasi yang dianggap penting untuk dijaga tingkat keamananya. Semakin bertambahnya permintaan akan ponsel atau smartphone ini dikarenakan terdapatnya fitur-fitur atau aplikasi di dalamnya yang dapat meringankan atau mempermudah suatu pekerjaan manusia[10]. Banyaknya aplikasi yang terdapat di dalamnya, dimana salah satunya dapat digunakan untuk mengontrol atau mengendalikan suatu hal yang dianggap penting. Setiap manusia menginginkan pekerjaannya dapat dikerjakan dengan santai, mudah dan ringan. Contohnya pada pintu air suatu bendungan yang menguras tenaga manusia untuk membukanya lalu menutupnya kembali. Pintu air merupakan tempat keluar atau pembuangan air yang banjir atau melebihi kapasitas dari suatu bendungan. Dengan semakin berkembangnya teknologi, penulis ingin mengkombinasikan antara smartphone android dengan instrumen mikrokontroller Atmega 328. Berdasarkan itulah dikembangkan sebuah "Prototype Pintu Air Berbasis Android Dan 
Mikrokontroller Menggunakan Bluetooth" .Alat ini berfungsi untuk memonitor dan mengontrol bendungan dengan alat pengontrol menggunakan smartphone android. Alat ini akan bekerja jika kedua device yaitu smartphone android terhubung dengan jaringan bluetooth. Agar kedua alat dapat membaca antara yang satu dengan yang satunya maka diperlukan perangkat lunak seperti App Invertor yang dapat di instal pada smartphone android dan personalcomputer. App Invertor sebuah aplikasi builder untuk membuat aplikasi yang berjalan di sistem operasi Android yang disediakan oleh googlelabs.

\section{METODE PENELITIAN}

Blok diagram merupakan gambaran secara umum dari alat prototype pintu air. Berdasarkan blok diagram ini dijelaskan fungsi masing-masing komponen yang saling terhubung sebagai I/O rangkaian. Seperti terlihat pada gambar 1 berikut.

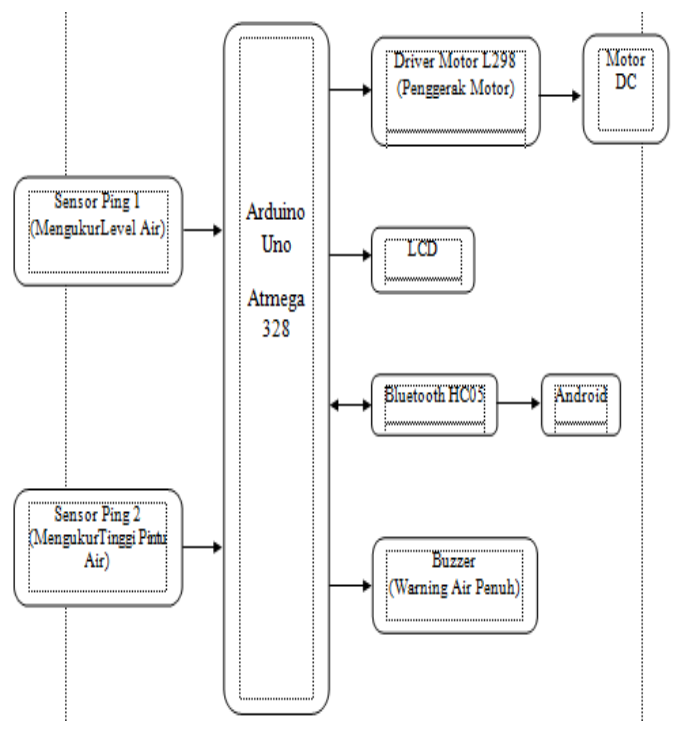

Gambar 1. Blok Diagram Prototype Pintu Air

Alat prototype pintu air ini bekerja secara otomatis. Sensor ping mengukur ketinggian air dan pintu air dan diolah oleh mikrokontroler lalu data dikirim ke android melalui bluetooth. Data pada android berupa data ketinggian air dan pintu air yang dideteksi dan akan ditampilkan pada layar LCD. Sedangkan buzzer sebagai tanda apabila air melebihi ketinggian $3 \mathrm{~cm}$ dan akan buzzer akan berbunyi. Pada alat ini android berfungsi sebagai alat monitoring dan control jarak jauh. Untuk dapat membuka dan menutup pintu air digunakan motor DC. Sehingga pintu air dapat dikontrol sesuai jarak perintah yang diberikan.

Level ketinggian air berdasarkan tingginya :

1. Level air $0-2 \mathrm{~cm}$ (aman)

2. Level air $2-3 \mathrm{~cm}$ (normal)

3. Level air $>3 \mathrm{~cm}$ (waspada buzzer bunyi).

\section{A. Perancangan Dan Pembuatan Perangkat Keras (Hardware)}

Pada gambar 2 dapat dilihat, Alat prototype pintu air ini bekerja secara otomatis. Sensor ping mengukur ketinggian air dan pintu air dan diolah oleh mikrokontroler lalu data dikirim ke android melalui bluetooth. Data pada android berupa data ketinggian air dan pintu air yang dideteksi dan akan ditampilkan pada layar LCD. Sedangkan buzzer sebagai tanda apabila air melebihi ketinggian $3 \mathrm{~cm}$ dan akan buzzer akan berbunyi. Pada alat ini android berfungsi sebagai alat monitoring dan control jarak jauh. Untuk dapat membuka dan menutup pintu air digunakan motor DC. Sehingga pintu air dapat dikontrol sesuai jarak perintah yang diberikan.

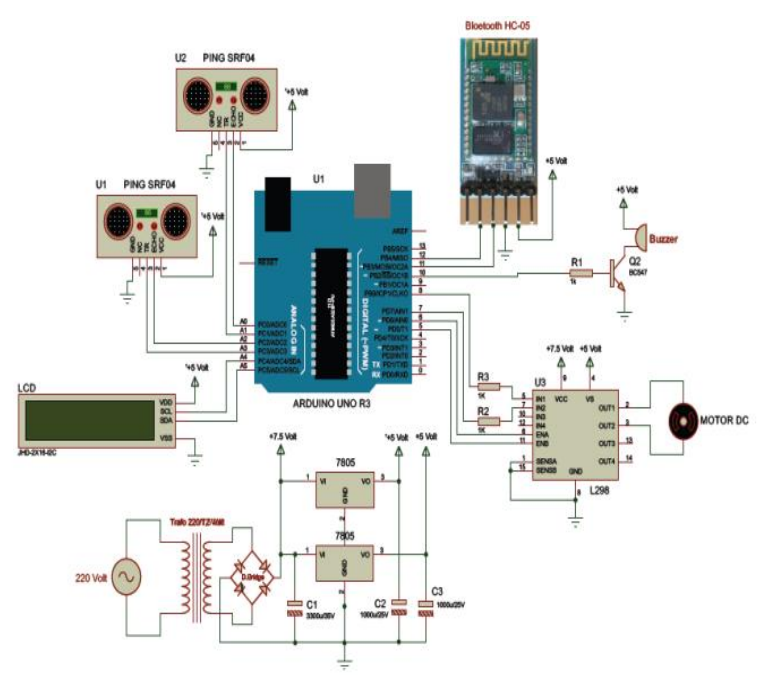

Gambar 2. Perancangan Dan Pembuatan Rangkaian Keseluruhan

\section{B. Perancangan Tampilan Android}

APP Inventor adalah sebuah aplikasi builder untuk membuat aplikasi yang berjalan di sistem operasi Android yang disediakan oleh googlelabs. Gambar 3 merupakan tampilan aplikasi mobile android menggunakan APP Inventor.

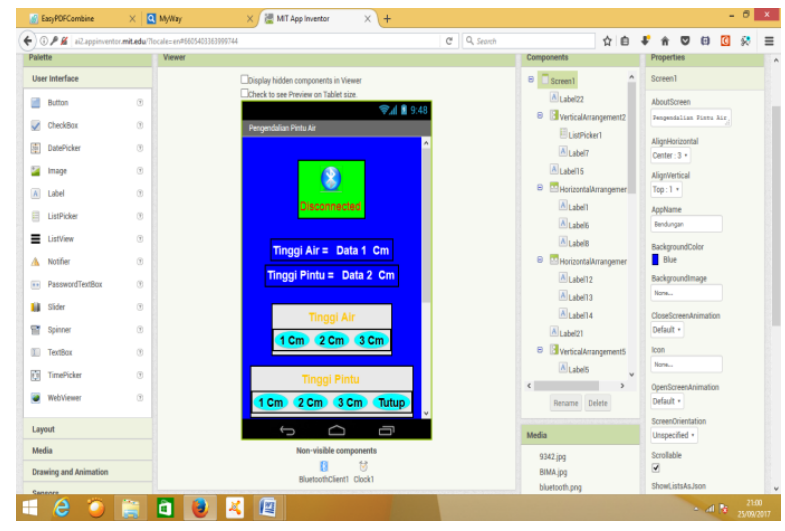

Gambar 3. Aplikasi App Invertor 


\section{Perancangan dan Pembuatan Mekanik}

Alat yang dibuat akan berupa pengendalian pintu air jarak jauh yang terdiri dari motor dc sebagai penggerak pintu,sensor ping sebagai mengukur ketinggian air dan ketinggian pintu air, lcd sebagai media tampilan data, dan bluetooth sebagai komunikasi serial data dari android ke rangkaian. Tampak keseluruhan pengendalian pintu air jarak jauh dapat dilihat seperti pada gambar 4 .

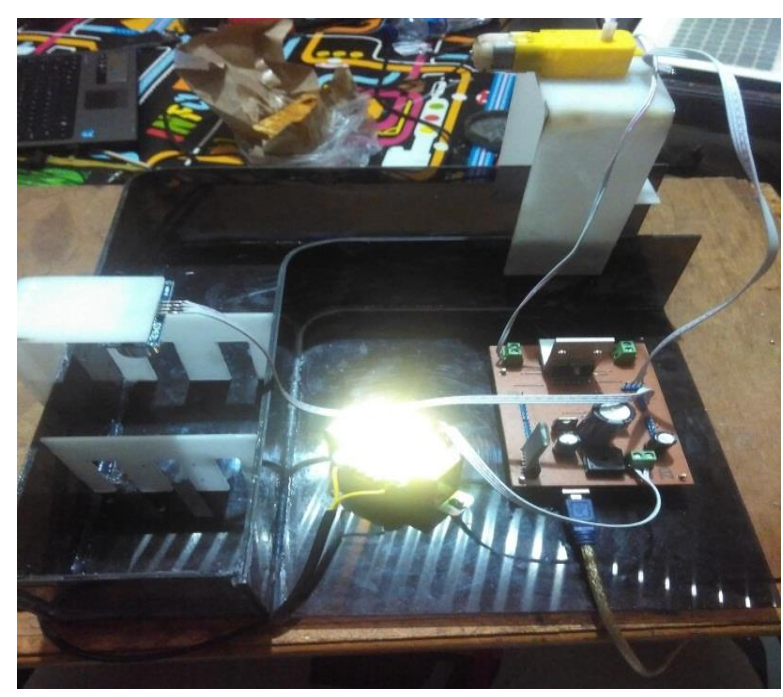

Gambar 4. Perancangan dan Pembuatan Tampak Keseluruhan

\section{HASIL DAN PEMBAHASAN}

Pengujian merupakan langkah penting didalam membuat sebuah alat dengan tujuan agar dapat mengetahui apakah pembuatan alat sudah sesuai dengan harapan atau ada kesalahan yang dapat mempengaruhi kinerja alat tersebut. Selain itu, pengujian seperti ini juga dapat untuk mengetahui kelebihan dan kekurangan dari system yang telah dibuat.Berikut adalah pokok pengujian dan analisa yang dilakukan:

1. Rangkaian bluetooth

2. Rangkaian sensor ping

3. Rangkaian driver motor

\section{A.Pengujian dan Analisa Rangkaian Bluetooth}

Setelah aplikasi terhubung dengan perangkat bluetooth, selanjutnya pengujian aplikasi yang terdapat pada smartphone android. Pada aplikasi terdapat kotak untuk menghubungkan dengan cara menekan kotak yang bergambar Bluetooth kemudian kita cari perangkat Bluetooth yang ada pada module Bluetooth di rangkaian. Berikut adalah tampilan yang digunakan untuk memasukkan password ke mikrokontroller ATMega328. Dapat dilihat pada gambar 5 berikut ini.

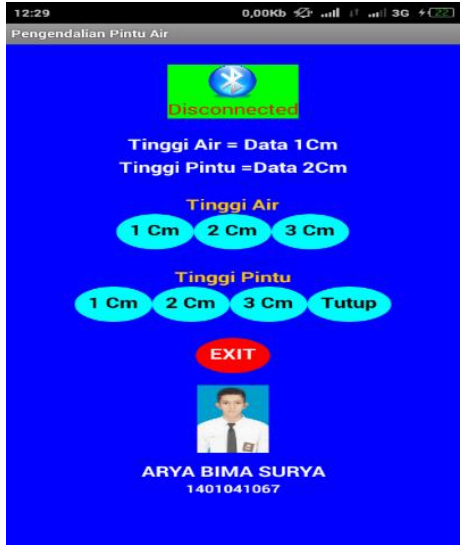

Gambar 5. Tampilan Menu Aplikasi Pada Android

Selanjutnya dilakukan pengujian apakah Bluetooth HC-05 dapat menerima informasi secara serial yang dikirim oleh Bluetooth Android, sejauh mana Bluetooth Android dapat mengirim data pada Bluetooth HC-05 yang akan dituliskan pada mikrokontroller dengan berbagai kondisi. Data hasil pengujian jarak yang memungkinkan untuk berkomunikasi antar Bluetooth Android dengan Bluetooth HC 05. Hasil pengujian dapat dilihat pada tabel 1 .

Tabel 1. Hasil pengujian pengiriman data Bluetooth

\begin{tabular}{cccl}
\hline Nomor & Jarak & $\begin{array}{c}\text { Android } \\
\text { Waktu Respon }\end{array}$ & Keterangan \\
\hline 1 & $2 \mathrm{M}$ & $0,6 \mathrm{~s}$ & Terhubung \\
\hline 2 & $5 \mathrm{M}$ & $0,7 \mathrm{~s}$ & Terhubung \\
\hline 3 & $10 \mathrm{M}$ & $0,8 \mathrm{~s}$ & Terhubung \\
\hline 4 & $15 \mathrm{M}$ & $1,0 \mathrm{~s}$ & Terhubung \\
\hline 5 & $20 \mathrm{M}$ & $1,2 \mathrm{~s}$ & Terhubung \\
\hline
\end{tabular}

Setelah melakukan pengujian pada Bluetooth HC-05 diperoleh hasil jika modul bluetooth HC-05 masih bisa menerima data sampai jarak 20 meter. Pada jarak 15 meter dan 20 meter waktu respon bluetooth menerima data lebih lama.

\section{B. Pengujian dan Analisa Sensor Ping}

Pengujian sensor ping ini bertujuan untuk mengetahui apakah pengukuran jarak oleh sensor sama dengan jarak yang sebenarnya. Sensor 1 untuk mengukur tinggi air dan sensor 2 untuk mengukur tinggi pintu air. Untuk pengujian kali ini data pengukuran jarak dari sensor ping ditampilkan pada LCD sedangkan perbandingan dengan jarak sebenarnya menggunkan meteran. Untuk membaca sensor 1 (sensor ketinggian air) agar air tidak beriak maka diksihlah steroform agar air bisa stabil dan bisa dibaca oleh sensor 1. Apabila tinggi air melebihi $3 \mathrm{~cm}$ maka buzzer berbunyi dan pintu air akan terbuka $3 \mathrm{~cm}$. Dalam melakukan pengukuran jarak yang terbaca oleh sensor dengan jarak sebenarnya terdapat kesalahan, dan untuk menentukan presentase kesalahan tersebut digunakan persamaan berikut : 


$$
\text { Eroor }=\frac{\text { Jarak pembacaan sensor }- \text { jarak sebenarnya }}{\text { Jarak pembacaan sensor }} \times 100 \%
$$

Hasil pengukuran data dapat dilihat pada tabel berikut :

Tabel 4. Hasil Pengukuran Jarak Rata-rata dan Persen Kesalahan

\begin{tabular}{cccccc}
\hline & & \multicolumn{2}{c}{ Jarak Pembacaan } & \multicolumn{2}{c}{ Kesalahan (\%) } \\
\cline { 3 - 6 } Nomor & Jarak & Sensor & Sensor & Sensor & Sensor \\
\cline { 3 - 6 } & Sebenarnya & $\mathbf{1}$ & $\mathbf{2}$ & $\mathbf{1}$ & $\mathbf{2}$ \\
& & (Tinggi & (Pintu & (Tinggi & (Pintu \\
& & Air) & Air) & Air) & Air \\
\hline 1 & $1 \mathrm{~cm}$ & $1,20 \mathrm{~cm}$ & $1,25 \mathrm{~cm}$ & $16 \%$ & $20 \%$ \\
\hline 2 & $2 \mathrm{~cm}$ & $2,28 \mathrm{~cm}$ & $2,39 \mathrm{~cm}$ & $12 \%$ & $16 \%$ \\
\hline 3 & $3 \mathrm{~cm}$ & $3,00 \mathrm{~cm}$ & $3,00 \mathrm{~cm}$ & $0 \%$ & $0 \%$ \\
\hline
\end{tabular}

Jika dilihat dari tabel pengujian, pada sensor 1 dan 2 ketika jarak sebenarnya $1 \mathrm{~cm}$ dan $2 \mathrm{~cm}$, pembacaan jarak oleh sensor 1 terjadi kesalahan sebesar $16 \%$ dan $20 \%$ dan sensor 2 terjadi kesalahan sebesar $12 \%$ dan 16 $\%$ hal ini dikarenakan sensor SRF04 hanya mampu membaca jarak terdekat sejauh $3 \mathrm{~cm}$. Untuk pembacaan sensor dari $3 \mathrm{~cm}$ tidak terjadi kesalahan atau dalam kata lain kesalahan pembacaan sensor hanya $0 \%$. Dimana semakin jauh jarak objek dari sensor maka kesalahan semakin besar.

\section{Pengujian dan Analisa Rangkaian Driver Motor}

Pengujian rangkaian driver motor L298 dilakukan untuk mengetahui apakah rangkaian dapat berfungsi dengan baik atau tidak. Pengujian driver motor menggunakan satu buah motor dc sebagai objek yang akan diatur oleh rangkaian komponen L298, dioda pada rangkaian driver motor untuk menghambattegangan balik yang dihasilkan oleh motor dc dan mengurangi tegangan yang ada pada motor agar motor berputar menjadi stabil. Arduino digunakan untuk menentukan kondisi tertentu (high/low) pada kaki input L298 sehingga motor dapat bergerak $\mathrm{CW}$ ataupun $\mathrm{CCW}$, bisa dilihat pada gambar berikut :

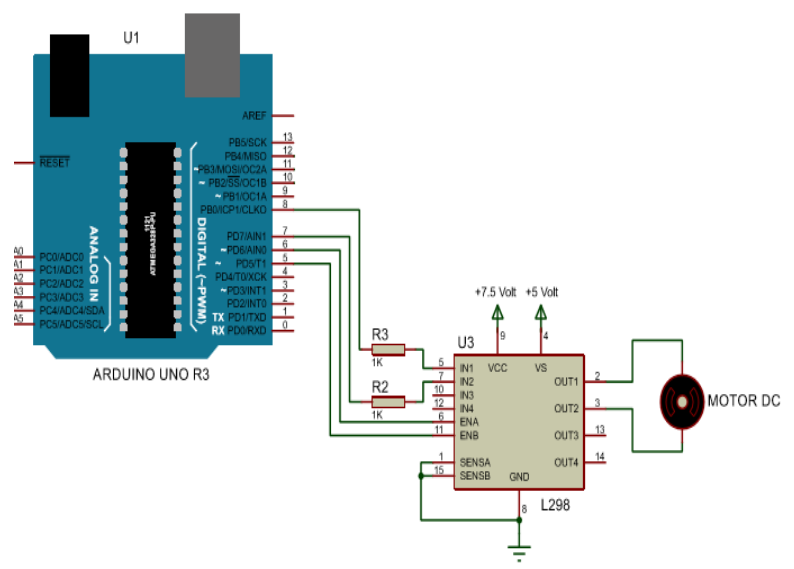

Gambar 6. Rangkaian Pengujian Driver Motor
Hasil pengukuran data dapat dilihat pada tabel berikut :

Tabel 4. Hasil Pengujian Rangkaian Driver Motor L298

\begin{tabular}{|c|c|c|c|c|}
\hline Nomor & \multicolumn{2}{|c|}{ PIN L298 } & \multirow{2}{*}{$\begin{array}{l}\text { Kondisi } \\
\text { Motor }\end{array}$} & \multirow{2}{*}{$\begin{array}{c}\text { Tegangan } \\
\text { (V) }\end{array}$} \\
\hline 1 & TP 1 & TP 2 & & \\
\hline 2 & 0 & 0 & Stop & $0,13 \mathrm{~V}_{\mathrm{DC}}$ \\
\hline 3 & 0 & 1 & $\mathrm{CW}$ & $4,27 \mathrm{~V}_{\mathrm{DC}}$ \\
\hline 4 & 1 & 0 & $\mathrm{CCW}$ & $4,25 \mathrm{~V}_{\mathrm{DC}}$ \\
\hline
\end{tabular}

Pada driver ini L298 berfungsi sebagai penggerak motor. Pada saat input 1 pada rangakain motor berlogika 0 dan input 2 pada rangkaian motor berlogika 0, maka kondisi motor tidak berputar atau stop dan tegangan yang dihasilkan 0,13 VDC. Pada saat input 1 pada rangkaian motor berlogika 0 dan input 2 pada rangkaian motor berlogika 1 , maka kondisi motor $\mathrm{CW}$ (Clock Wise) dan tegangan yang dihasilkan 4,27 VDC. Sebaliknya saat input 1 pada rangkaian motor berlogika 1 dan input 2 berlogika 0 , maka kondisi motor CCW (Counter Clock Wise) dan tegangan yang dihasilkan $4,25 \mathrm{Vdc}$

\section{KESIMPULAN}

Apabila ketinggian permukaan air berada dalam rentang $0 \mathrm{~cm}$ sampai $2 \mathrm{~cm}$ bertanda permukaan normal dan pintu masih tertutup dan apabila ketinggian air lebih dari $3 \mathrm{~cm}$ pintu bendungan akan terbuka alarm buzzer akan berbunyi. Kemudian apabila ketinggian permukaan kembali normal (kurang dari $3 \mathrm{~cm}$ atau kecil sama dengan $1 \mathrm{~cm}$ ) maka pintu bendungan akan kembali menutup otomatis

Proses pengiriman data bluetooth menggunakan Modul HC-05 membutuhkan delay sekitar 0.6 detik sampai 1 detik ketika kondisi bluetooth tanpa halangan, sedangkan pada saat kondisi bluetooth ada halangan proses pengiriman bluetooth membutuhkan delay hingga mencapai 5 detik, tergantung ada atau tidak adanya halangan di area tersebut.

\section{REFERENSI}

[1] P. B. de Moura Oliveira. Teaching automation and control with App Inventor applications. 2015 IEEE Global Engineering Education Conference (EDUCON). Tallinn, Estonia

[2] Murat Karakus. Suleyman Uludag. Evrim Guler. Stephen W. Turner. Ahmet Ugur. Teaching computing and programming fundamentals via App Inventor for Android. 2012 International Conference on Information Technology Based Higher Education and Training (ITHET). Istanbul, Turkey

[3] Dhiraj Sunehra ; M. Veena. Implementation of interactive home automation systems based on email and Bluetooth technologies. 2015 International Conference on Information Processing (ICIP). Pune, India

[4] Akhmad Zainuri, Unggul Wibawa, Eka Maulana. Implementasi Bluetooth HC-05 untuk Memperbarui Informasi Pada Perangkat Running Text Berbasis Android. Jurnal EECCIS Vol. 9, No. 2, Desember 2015. 163-167 
[5] Ranjbar MR, Abdalla AH. Development of an Autonomous Remote Access Water Quality Monitoring System. Indonesian Journal of Electrical Engineering and Computer Science. 2017; 8(2): 467-474.

[6] Bhandari V, Abrol P. Field Monitoring of Treated Industrial Waste Water. International Journal of Electrical and Computer Engineering (IJECE). 2013; 3(5): 629-634.

[7] Offiong NM, Abdullahi SA, Chile-Agada BUN, Raji-Lawal HY, Nweze NO. Real Time Monitoring of Urban Water System for Developing Countries. IOSR-JCE. 2014; 16(3): 11-14.

[8] Kadir, Abdul.2013.Paduan Praktis Mempelajari Aplikasi Mikrokontroler danPemogramannya Menggunakan Arduino. Edisi 22. Yogyakarta: Andi Yogyakarta.

[9]Malvino Hanafi Gunawan. 1994 “Prinsip Prinsip Elektronika (edisi kedua)”.Jakarta : Erlangga. 